\title{
LA DECLARACIÓN DEL RIESGO EN LOS SEGUROS PARA PERSONAS: DEBER DE INFORMACIÓN Y DEBER DE INFORMARSE*
}

\section{THE DECLARATION OF THE RISK FOR PERSONAL INSURANCE: DUTY OF INFORMATION AND DUTY TO BE INFORMED}

\author{
ALONSO NÚNEEZ DEL PRADO SIMONS **
}

Fecha de recepción: 25 de septiembre de 2017

Fecha de Aceptación: 4 de abril de 2018

Disponible en linea: 30 de junio de 2018

\section{Para Citar este articulo/To cite this article}

Núñez del Prado Simons, Alonso, La declaración del riesgo en los seguros para personas: deber de información y deber de informarse, 48 Rev.IberoLatinoam.Seguros, 41-62 (2018). https://doi.org/10.11144/Javeriana.ris48. drsp

doi:10.11144/Javeriana.ris48.drsp

* Esta es la Conferencia que el 5 de mayo de 2017 dictó el autor en el Congreso del Comité IberoLatinoamericano (CILA) de la Association Internationale de Droit des Assurances (AIDA) en Santa Cruz de la Sierra, Bolivia.

** Abogado, cursó el Magíster en Derecho de la Integración y el de Derecho Constitucional, es Master of Business Administration (MBA) por el College of Insurance de Nueva York, graduado en Lingüística y Literatura, además de en Filosofía, en que también cursó el Magíster. Es fundador y Director Ejecutivo del 'Observatorio de cumplimiento de planes de gobierno', profesor universitario, árbitro y conferencista internacional. Es autor del libro 'Los secretos de los seguros' y publica habitualmente en revistas jurídicas y en los principales diarios de Lima. Asimismo, es Presidente de la 'Asociación Peruana de Derecho de Seguros', Capítulo de AIDA en el Perú y director de varias entidades del sistema asegurador. Contacto: alonso.nezdelprado@gmail.com 


\section{RESUMEN}

El autor analiza la declaración del riesgo en los seguros de personas en la legislación peruana con especial énfasis en el deber de buena fe de las partes.

Palabras clave: Seguros de personas; declaración del riesgo; seguros de vida; seguros médicos. 


\section{ABSTRACT}

The author analyzes the declaration of the risk in personal insurance in the Peruvian Legislation with special emphasis in the duty of good faith of the parties.

Keywords: Personal insurance; declaration of the risk; life insurance; medical insurance.

\section{SUMARIO}

INTRODUCCIÓN. A. Doctrina de la máxima buena fe. B. La declaración del riesgo en la legislación peruana. 1. La solicitud. 2. La reticencia y/o declaración inexacta. a) Dolo o culpa inexcusable. b) No dolosa. 3. Diferencias entre la propuesta o la publicidad y la póliza y el cambio en las condiciones contractuales. a) Propuesta. b) Condiciones contractuales. c) Publicidad. 4. Cláusulas y prácticas abusivas. a) Cláusulas abusivas. b) Prácticas abusivas. 5. Fraude y provocación del siniestro. 6. Cargas de las partes. C. Seguro de personas. 1. Definición y ámbito de aplicación. 2. Seguro de salud. 3. Seguro de vida. a) Definición. b) Consentimiento en casos de seguros para tercero. c) Incontestabilidad o indisputabilidad. d) Declaración inexacta de la edad. e) Agravación del riesgo. f) Suicidio y muerte del tercero por el contratante y/o beneficiario. g) Resolución y liberación del asegurador. h) Derechos del Asegurado. i) Seguro de vida en beneficio de un tercero. j) Proporción entre beneficiarios. k) Falta de designación de beneficiarios. 1) Forma de la designación. m) Liquidación patrimonial. 4. Seguro de accidentes personales. a) Definición. b) Pago inmediato. c) Dolo del asegurado o del beneficiario. 5 . Seguro de grupo. BIBLIOGRAFÍA 


\section{INTRODUCCIÓN}

La nueva Ley 29946 del contrato de seguro (LCS), promulgada el 27 de noviembre de 2012 y vigente en el Perú 180 días después, es decir desde el 27 de mayo de 2013, tiene incluida la buena fe como el primero de sus principios, establecidos en el artículo II de las Disposiciones Generales, una especie de título preliminar de la norma. En consecuencia, también acoge la idea de que la buena fe es necesaria para ambas partes. Lo que además es aplicable -como es conocido- a cualquier contrato.

La mayor parte de la ley peruana (Arts. 9 al 15 de la LCS) sobre buena fe, se refiere a los deberes del asegurado de proveer al asegurador de información antes de que se inicie la vigencia el contrato. Empero, como está generalmente aceptado en la doctrina y en el Derecho comparado, en la ley peruana (Arts. 59 al 73) se establece que el deber de buena fe no está limitado a asuntos pre-contractuales; sino que se aplica a la forma en que las partes se comportan mutuamente después que el contrato ha sido formalizado.

Merece especial mención el artículo 6 de la LCS que incorpora el 'sistema del cuestionario' de uso general en los seguros de personas y que podría soslayar la obligación del asegurado de declarar toda la información de importancia respecto del riesgo. Establece que:

\section{Artículo 6. Contenido de la solicitud de seguro}

El texto de la solicitud de seguro es suministrado por el asegurador. Las condiciones generales, particulares y especiales que forman parte de la póliza deben estar a disposición previa del solicitante para integrarse al contrato. La solicitud deberá ser firmada por el contratante del seguro, salvo en el caso de contratos comercializados a distancia.

Esta norma traslada a la aseguradora el deber de elaborar una solicitud que tenga preguntas que le permitan conocer el riesgo con detalle, pero ésta suele incluir una final que invita al solicitante a informar cualquier otro asunto que considere de importancia y de esa manera evita cerrar la información al cuestionario y abren la posibilidad de alegar mala fe, aunque la solicitud no incluyera una pregunta específica sobre un determinado aspecto. Las aseguradoras pueden además (piden se les autorice a hacerlo en la solicitud) pedir información a otras entidades y o personas (médicos), pero están prohibidos de hacerlo respecto de 
exámenes genéticos (Art. 119 de la LCS). Tienen además la obligación de confidencialidad relativa a la información que reciban derivada del derecho constitucional a la intimidad. El tratamiento a la cobertura de preexistencias en los seguros médicos ha tenido una evolución favorable en el Perú y hoy no sólo es necesario que la dolencia le haya sido diagnosticada al asegurado (segundo párrafo del artículo 118 de la LCS), sino que también es obligatorio cubrirlas sin recargos si el asegurado estuvo cubierto previamente por otra compañía y una Entidad Prestadora de Salud (EPS) y contrata dentro de los siguientes 90 días.

Los miembros de la Comisión que redactó el Proyecto - que luego se convirtió en ley-consideramos adecuado optar por la preservación del contrato (artículo $15^{\circ}$ ) abandonando la doctrina inglesa que había prevalecido en el Código de Comercio de 1902. Decidimos seguir el camino del Derecho Continental Europeo (Alemania, Francia, España, Italia), del que el nuestro es heredero, que busca preservar el contrato en los casos de reticencias o declaraciones inexactas no dolosas. El Derecho inglés y el Código de Comercio (artículo $376^{\circ}$ ) vigente hasta el 27 de mayo de 2013, cuando entró en vigencia la nueva Ley, permitían que el asegurador deduzca la nulidad del contrato si la reticencia o información inexacta es relevante. En otras palabras, preferimos limitar la opción de nulidad del contrato a sólo casos de dolo y culpa inexcusable, lo que con frecuencia han olvidado mencionar los aseguradores cuando criticaban el giro que se estaba haciendo con la nueva Ley. Lo que en realidad incomoda de este cambio es que se está limitando la enorme discrecionalidad con que contaban las compañías para decidir su posición frente a los siniestros en que existía alguna falta del asegurado.

El concepto de 'mala fe' se aplicaba básicamente al asegurado hasta que las cortes inglesas recordaron que la Marine Insurance Act exigía buena fe a las dos partes y las cortes estadounidenses las siguieron.

Como antes indiqué la mala fe puede ser pre-contractual y en el caso del asegurador está relacionada directamente con la redacción del contrato que en la mayor parte de países está normado por la Ley del contrato de seguro (LCS) que lo regula.

En el caso peruano los artículos $(39,40$ y 41$)$ de la LCS relacionados con las cláusulas abusivas son ejemplo de cómo se sanciona la mala fe 
del asegurador cuando incluye éstas en las pólizas: 'son nulas de pleno derecho por lo que se las tiene por no convenidas'.

En pocas palabras, en el Derecho comparado, usualmente, la propia ley o, en algunos casos la jurisprudencia, sancionan a los aseguradores que tomando ventaja de ser los redactores de los contratos se permiten incluir condiciones inaceptables en éstos, porque desequilibran de manera importante los derechos y deberes de las partes.

En cuanto a la mala fe post contractual, el proceder de un asegurador desde que el siniestro le fue denunciado, puede entenderse como la afirmación del contrato de seguro y la renuncia a cualquier impugnación; sobre todo si se le agrega una demora no justificada y excesiva antes de su pronunciamiento. Lo expuesto implica un proceder poco profesional, negligente y que no respeta el principio de máxima buena fe que como indiqué es obligatorio para las dos partes en todo contrato, pero especialmente en el de seguros.

\section{A. Doctrina de la máxima buena fe}

Durante muchos siglos, la relación entre una persona que busca un seguro y la aseguradora que se lo proporciona se ha definido bajo lo que se conoce como la doctrina de la máxima buena fe -uberrima bona fidei.

Desde los primeros días de los seguros marítimos, pasando luego a otras formas, el peso de revelar todos los hechos relevantes, ha descansado sobre el proponente. Esto significa que éste debe proporcionar toda la información que posea y sea importante respecto al riesgo.

Y ¿qué es un 'hecho importante'? Se le ha definido como aquel que influenciaría a un asegurador prudente en la aceptación del riesgo; y, de hacerlo, qué tarifa debería cobrar por éste.

En Inglaterra, en una sentencia muy antigua -Carter vs. Boehm de 1766- el juez, Lord Mansfield, resumió esta doctrina diciendo:

"El seguro es un contrato en base a una especulación. Los hechos especiales sobre los que se debería calcular el riesgo contingente, por lo general, son conocidos sólo por el asegurado. El asegurador confía en lo que éste manifiesta y actúa en la confianza de que el asegurado no se está reservando circunstancia alguna que 
él conozca, para engañarlo tratando que crea que no existe tal, induciéndolo a estimar el riesgo como si este no existiera... Aunque la omisión ocurriera por error, sin intención fraudulenta, el asegurador habrá sido engañado y la póliza es nula; porque el riesgo corrido es en realidad diferente al que se entendió y que se pensaba asumir al momento del convenio".

Este principio fue incluido más adelante en la Ley de Seguro Marítimo (Marine Insurance Act) de 1906, Secc.18, donde se define el nivel de la obligación de la siguiente manera:

"El asegurado deberá revelar al asegurador, antes de celebrar el contrato, toda circunstancia material que conozca y se considera que conoce todas las circunstancias, que en el curso normal de su negocio, deberían ser conocidas por él. Si el asegurado omitiera hacer tal revelación, el asegurador podrá invalidar el contrato".

El segundo párrafo agrega:

"Toda circunstancia que podría influenciar el raciocinio del asegurador prudente para fijar la prima o para determinar si asume el riesgo, es relevante".

Como se puede ver, es muy importante que el proponente de un seguro cumpla con la doctrina de la máxima buena fe. No está demás agregar, que a estas alturas la obligación de revelar recae también en el asegurador.

Otro caso histórico del derecho inglés que terminó en los tribunales londinenses, el de Bufe vs. Turner, cuya audiencia se celebró en 1815, nos servirá de introducción para el análisis de esta doctrina.

No lejos del taller de un constructor de botes, un hombre tenía un almacén. Al producirse un incendio en el taller, el propietario del almacén se percató, con alarma, que no tenía cobertura contra incendio. Parecía que se había extinguido el incendio antes de que llegara a su almacén, recordando que no estaba asegurado, solicitó de inmediato una cobertura, omitiendo mencionar el incendio en el taller vecino. Por desgracia, el incendio no había sido adecuadamente extinguido y dos días después se volvió a encender y se extendió al almacén. Más tranquilo, ya que había obtenido la cobertura que solicitara, presentó su reclamo, pero al asegurador esto no le pareció muy transparente, ya que al estudiar la solicitud de seguro se encontró que no había mención al incendio ocurrido dos 
días antes. Por lo tanto, rechazó el siniestro, arguyendo que no se había revelado un hecho importante. En otras palabras, sostuvo que su decisión de otorgar el seguro, habría sido diferente si se le hubiera proporcionado la información respecto al incendio anterior. Al no poder cobrar, el dueño del almacén decidió recurrir al Poder Judicial para cobrar la indemnización, pero el juez apoyó la negativa del asegurador sosteniendo en la sentencia que se había incumplido la obligación de la máxima buena fe.

En base a éste y a otros casos similares podemos ver que proporcionar toda la información importante es un deber fundamental y que la consecuencia de su incumplimiento, es decir, la violación de este principio, hacía -en la Inglaterra de ese entonces- anulable la póliza a opción de la parte agraviada; pero lo que constituye un hecho importante, puede resultar siendo algo que tenga que ser decidido en la vía judicial y de acuerdo a cada caso particular.

La larga historia del seguro y los múltiples fallos judiciales en ese período, han establecido algunos hechos que no requieren revelarse. Algunos de ellos son:

a) Hechos que mejoran el riesgo. Así se podrá proteger un edificio mediante equipos contra incendio o un sistema de alarma, sin comunicárselo al asegurador.

b) Hechos que debería conocer un asegurador competente como parte de su trabajo. Por ejemplo, debería estar bien informado sobre las zonas en conflicto o que pueden ser en especial peligrosas, debido a fenómenos naturales, más aún si es que corresponden a los lugares a que alcanza su cobertura.

c) Requerimientos legales pertinentes con los que un asegurador debería estar familiarizado, como la legislación que rige la cobertura de un vehículo automotor.

d) Hechos que hubiera conocido si hubiera realizado una averiguación. Si llenando un formulario (la solicitud) el proponente al responder una pregunta contenida en el mismo, respecto a los antecedentes del seguro indica: "Consultar sus propios archivos", el asegurador, deberá hacerlo. Si no lo hace no podrá argumentar una falta contra la buena fe.

e) Hechos que se le escapen al asegurador cuando envía a su representante a realizar una inspección, siempre que el proponente no se los haya ocultado.

Si bien es cierto que en general estos hechos no requieren ser revelados, una decisión definitiva al respecto sólo podrá tomarse luego de que se amerite todos los demás detalles que rodeen al caso específico. 
Con frecuencia ocurre que al buscar una cobertura de seguros alguna otra persona - por lo general el corredor-actúa a nombre del proponente. El deber de ejercer la máxima buena fe, descansa igualmente sobre sus hombros y el hecho de que un agente o el representante de un bróker, no cumpla con revelar de forma plena los hechos, se considera como un incumplimiento del titular. Esta es una afirmación válida en términos generales, pero que debería ser evaluada al detalle en la casuística.

La máxima buena fe debe existir durante las negociaciones del contrato y debe continuar hasta el momento que caduca o se hace efectiva la póliza. Entonces, para algunos seguros tales como los de incendio y robo, existe una condición que señala de manera expresa, que durante su vigencia, se deberá notificar al asegurador de cualquier cambio que aumente el riesgo y para el cual podría requerirse una prima adicional.

Más en el caso de seguros de vida, es diferente, ya que la obligación cesa con el pago de la primera prima. Así tenemos que si un empleado bancario obtiene una póliza y luego entra a trabajar desactivando explosivos, no requiere comunicar este cambio, siempre y cuando no fuera su intención cambiar de ocupación al momento de contratar el seguro.

La información y los hechos proporcionados por un proponente y posterior asegurado, forman parte del contrato de seguros, porque representan, reflejan o describen el riesgo para el asegurador. Deben, en consecuencia, ser substancialmente correctos, esto es, al leal saber y entender del proponente. En las solicitudes suele incluirse al final una declaración que reitera que las respuestas son ciertas y completas al leal saber y entender del firmante. Esto tiene el efecto de transformar la información y los hechos proporcionados en garantías.

La doctrina en materia contractual, en relación a los seguros, ha refrendado esta afirmación sosteniendo que habiendo el asegurador celebrado el contrato en base a la información proporcionada, las declaraciones del asegurado se convierten en garantías y son declaraciones fundamentales para el contrato, por lo que en el caso de que la información sea incompleta o equívoca, el primero tiene la opción de anularlo.

Veamos ahora, algunas de las maneras en las que podría violarse este deber de la máxima buena fe. 
En forma inocente el solicitante de un seguro podría:

Dejar de comunicar alguna información vital, por olvido o por no darse cuenta que es importante, es decir una omisión. Un caso se daría cuando el solicitante de un seguro de vida omite revelar que cuando niño había sufrido fiebre reumática. Las solicitudes-propuesta no siempre incluyen una pregunta sobre esta enfermedad y el solicitante puede no percatarse de su importancia.

Proporcionar información que cree correcta cuando en realidad no lo es. Es conocida como falsa declaración inocente y podría ocurrir cuando, por ejemplo, el arrendador de un inmueble describió el trabajo que realizaba su inquilino como "de ingeniería" cuando sin que él lo supiera, el inquilino hubiera incursionado en la fabricación de productos plásticos;

o podría ir aún más lejos, y deliberadamente

Ocultar un hecho relevante-como mencionamos antes en el caso de Bufe vs. Turner- lo que constituye un ocultamiento; o

Llegar hasta el punto de proporcionar información falsa.

Si, como con frecuencia sucede, los verdaderos hechos sólo salen a la luz a consecuencia de una pérdida, el asegurador tendrá que decidir si la violación es lo suficientemente seria como para que se niegue a aceptar el reclamo. Y ésta es una decisión que debe ser revisada cuidadosamente, porque el rechazo de una reclamación puede tener que justificarse más adelante en la vía judicial, con los consecuentes sobre costos.

Por sus eventuales consecuencias en la doctrina de la máxima buena fe y por lo interesante que resulta jurídicamente, vale la pena comentar el caso inglés de la Ley de rehabilitación del trasgresor de 1974 (Rehabilitation of Offenders Act). Esta ley modificó la obligación de revelar información. Así una persona que ha sido condenada, ha cumplido su condena y ha rehabilitada por el paso del tiempo estipulado, tiene derecho a considerar la condena como "extinguida". En consecuencia, puede hablar y actuar como si nunca hubiera cometido el delito ni hubiese sido condenada. Más aún, tiene el derecho de denunciar (iniciar una querella 
en nuestro caso) por difamación, contra cualquiera que revele su prontuario. Alguien que estuviese enterado de los hechos, por ejemplo un corredor que esté tramitando el seguro de su cliente, puede encontrarse con que tiene que mentir -"verdad legal"- con el respaldo de la ley. Si más adelante, al investigarse un reclamo, sale a luz una condena "extinguida", ésta no constituye causal de rechazo para un asegurador.

\section{B. La declaración del riesgo en la legislación peruana}

\section{La solicitud}

El artículo 5 de la LCS señala que la solicitud del seguro, cualquiera sea su forma, no obliga al contratante ni al asegurador. De otro lado el artículo 6 indica que el texto de la solicitud es suministrado por el asegurador y que las condiciones generales, especiales, y particulares y que forman parte de la póliza deben estar a disposición previa del solicitante para integrarse al contrato. Además, que la solicitud deberá ser firmada por el contratante del seguro, salvo en el caso de contratos comercializados a distancia.

\section{La reticencia $y / 0$ declaración inexacta}

\section{a. Dolo o culpa inexcusable}

El artículo 8 dice que la reticencia y/o declaración inexacta de circunstancias conocidas por el contratante y/o asegurado, que hubiese impedido el contrato o modificado sus condiciones si el asegurador hubiese sido informado del verdadero estado del riesgo, hace nulo el contrato si media dolo o culpa inexcusable del contratante y/o asegurado; y el artículo 9 agrega que el asegurador dispone de un plazo de treinta (30) días para invocar la nulidad, plazo que debe computarse desde que el asegurador conoce la reticencia o declaración inexacta, lo que debe ser notificado por medio fehaciente.

La carga de la prueba de la reticencia y/o declaración inexacta corresponde al asegurador quien, para tal efecto, puede valerse de todos los medios de prueba consagrados en el ordenamiento jurídico.

En estos casos (dolo o culpa inexcusable) las primas pagadas quedan adquiridas por el asegurador, quien tiene derecho al cobro de las acorda- 
das para el primer año de duración del contrato a titulo indemnizatorio (Art. 11); y si el siniestro se produce antes del vencimiento del plazo se encuentra liberado del pago de la prestación (Art. 12).

\section{b. No dolosa}

Si la reticencia y/o declaración inexacta no obedece a dolo o culpa inexcusable del contratante y/o asegurado y es anterior a la ocurrencia del siniestro, el asegurador debe ofrecer al contratante una revisión del contrato en un plazo de treinta días computados desde la constatación. El ofrecimiento puede incluir un reajuste de primas y/o en la cobertura y otorgar un plazo de diez días para que el contratante se pronuncie. Si la revisión y el reajuste de la prima es aceptado se paga según lo acordado, pero de lo contrario el asegurador puede resolver el contrato mediante comunicación en el plazo de treinta días computados desde el vencimiento del plazo de diez días antes indicado, reteniendo las primas devengadas a prorrata, hasta el momento en que efectuó la resolución (Art. 13).

Si la constatación es posterior a la ocurrencia del siniestro, la indemnización se reduce en proporción a la diferencia entre la prima convenida y la que se hubiese aplicado de haberse conocido el estado del riesgo (Art. 14)

El artículo 15 de la LCS indica que en los casos de reticencia y/o declaración inexacta no procede la nulidad, revisión o resolución del contrato cuando:

a) Al tiempo del perfeccionamiento del contrato, el asegurador conoce o debe conocer el verdadero estado del riesgo g.

b) Las circunstancias omitidas o declaradas en forma inexacta cesaron antes de ocurrir el siniestro o cuando, la reticencia o declaración inexacta no dolosa, no influyó en la producción del siniestro ni en la medida de la indemnización o prestación debida.

c) Las circunstancias omitidas fueron contenido de una pregunta expresa no respondida en el cuestionario y el asegurador igualmente celebró el contrato.

d) Las circunstancias omitidas o declaradas en forma inexacta disminuyen el riesgo $f$. 


\section{Diferencias entre la propuesta o la publicidad y la póliza y el cambio en las condiciones contractuales}

\section{a. Propuesta}

Cuando el texto de la póliza difiere del contenido de la propuesta u oferta, la diferencia se considera tácitamente aceptada por el contratante si no reclama dentro de los treinta días de haber recibido la póliza. Esta aceptación se presume sólo cuando el asegurador advierte al contratante, en forma detallada y mediante documento adicional y distinto a la póliza, que existen esas diferencias y que dispone de treinta días para rechazarlas. Si la referida advertencia es omitida por el asegurador, se tendrá las diferencias como no escritas salvo que sean más beneficiosas para el asegurado. Para producir efectos antes de los 30 días, la aceptación de las diferencias por parte del contratante deberá ser expresa. La eliminación o el rechazo de las diferencias no afectan la eficacia del contrato en lo restante, salvo que comprometan la finalidad económico-jurídica del contrato (Artículo 29).

\section{b. Condiciones contractuales}

Durante la vigencia del Contrato el asegurador no puede modificar los términos contractuales pactados sin la aprobación previa y por escrito del contratante, quien tiene derecho a analizar la propuesta y tomar una decisión en el plazo de treinta días desde que la misma le fue comunicada. La falta de aceptación de los nuevos términos no genera la resolución del contrato, en cuyo caso se deberá respetar los términos en los que el contrato fue acordado (Art. 30).

\section{c. Publicidad}

Cuando existan diferencias entre las condiciones del seguro ofrecidas mediante sistemas de publicidad y el contenido de la póliza, relativos al mismo seguro, prevalecen las condiciones más favorables para el asegurado (Art. 31).

\section{Cláusulas y prácticas abusivas}

La LCS ha previsto (Art. 39) otros requisitos de transparencia, relacionados con la forma y redacción de los contratos de seguros, disponiendo que 
las condiciones generales, especiales y particulares que sean aplicables al contrato deben cumplir con los siguientes requisitos:

- Concreción, claridad y sencillez en la redacción que permita comprensión directa, sin reenvíos a cláusulas y pactos no contenidos en la póliza.

- Estar ajustadas a la buena fe y justo equilibrio entre los derechos de las partes.

\section{a. Cláusulas abusivas}

Con relación al segundo requisito y al principio de máxima buena fe que acabo mencionar, la LCS establece los siguientes criterios para determinar el carácter abusivo de las cláusulas:

1) Son aquellas estipulaciones no negociadas que, aun cuando no hayan sido observadas por la SBS, afecten la buena fe en perjuicio del asegurado, y causen un desequilibrio importante en los derechos y obligaciones de las partes. Se considera que una cláusula no se ha negociado cuando ha sido redactada previamente y el contratante no ha influido en su contenido.

2) Que ciertos elementos de una cláusula o que una cláusula aislada se haya negociado no excluirá la aplicación al resto del contrato, si la apreciación global lleva a la conclusión de que se trata de un contrato por adhesión.

3) El carácter abusivo de una cláusula se apreciará teniendo en cuenta, además de la situación ventajosa que genere para el asegurador en perjuicio del asegurado, la naturaleza de los bienes o servicios materia del contrato y de su celebración, así como el resto de cláusulas del contrato.

4) Es abusiva una cláusula aun cuando el asegurado la haya aprobado.

5) Las cláusulas abusivas son nulas de pleno derecho (no convenidas).

6) Cuando el juez declare la nulidad parcial del contrato puede integrarlo si es que puede subsistir sin ver comprometida su finalidad económico-jurídica. 
7) Las cláusulas o prácticas abusivas no dejan de serlo por el hecho de que en la celebración del contrato de seguro haya participado un corredor de seguros.

\section{b. Estipulaciones prohibidas}

Asimismo, la LCS establece prohibiciones a la inclusión de estipulaciones desventajosas o perjudiciales a los asegurados, sancionándolas con la nulidad de pleno derecho. Señala con carácter enunciativo las siguientes:

1) Cláusulas mediante las cuales los asegurados y/o beneficiarios renuncien a la jurisdicción y/o leyes que les favorezcan.

2) Cláusulas que establezcan plazos de prescripción que no se adecúen a la normativa vigente.

3) Cláusulas que prohíban o restrinjan el derecho del asegurado a someter la controversia a la vía judicial, sin perjuicio de su derecho de acordar con el asegurador, recién una vez producido el siniestro, el sometimiento del caso a arbitraje u otro medio de solución de controversias.

4) Cláusulas que dispongan la pérdida de derechos del asegurado y/o beneficiario por incumplimiento de cargas que no guardan consistencia ni proporcionalidad con el siniestro cuya indemnización se solicita.

5) Cláusulas que limitan los medios de prueba que puede utilizar el asegurado o que pretendan invertir la carga de la prueba en perjuicio del asegurado.

6) Cláusulas que establecen la caducidad o pérdida de derechos del asegurado en caso de incumplimiento de cargas excesivamente difíciles o imposibles de ser ejecutadas.

7) Cláusulas que imponen la pérdida de derechos del asegurado en caso de violación de leyes, normas o reglamentos, a menos que esta violación corresponda a un delito ó constituya la causa del siniestro.

8) Otras que establezca la SBS en protección de los intereses de los asegurados. 
De otro lado, la LCS, faculta a la SBS para identificar las cláusulas abusivas y emitir normas de carácter general que prohíban su inclusión en futuros contratos y la obligación de difundir las que hayan sido identificadas.

Otra medida de transparencia es que en la redacción de los condicionados, debe consignarse en caracteres resaltados determinadas partes de la póliza que revistan especial interés para el contratante o asegurado, debido a que la LCS establece que se tendrán por no escritas las cláusulas que consagran caducidades a los derechos del asegurado, suspensiones o exclusiones de cobertura contenidas en las condiciones generales o especiales predispuestas o en anexos, que no se encuentren impresas en caracteres notorios. Además, en caso de imponerse cláusulas de garantía que condicionen la cobertura del riesgo al asegurado, es decir cargas adicionales y especiales se debe destacar su existencia, en la parte frontal de la póliza.

\section{Fraude y provocación del siniestro}

El asegurado pierde el derecho a ser indemnizado si actúa fraudulentamente, exagera los daños o emplea medios falsos para probarlos (Art. 73).

De otro lado, el asegurador queda liberado si el contratante o, en su caso, el asegurado, o el tercero beneficiario, provocan el siniestro dolosamente o por culpa grave, salvo pacto en contrario con relación a esta última. En este caso, quedan excluidos los actos realizados para evitar el siniestro o atenuar sus consecuencias, por un deber de humanidad generalmente aceptado, por legítima defensa, estado de necesidad o cumplimiento de un deber legal (Art. 91).

\section{Cargas de las partes}

Corresponde al asegurado demostrar la ocurrencia del siniestro, así como la cuantía de la pérdida si fuera el caso, y al asegurador la carga de demostrar las causas que lo liberan de su prestación indemnizatoria (Art. 77). 


\section{Seguro de personas}

\section{Definición y ámbito de aplicación}

El seguro de personas recae sobre la vida del asegurado o de un tercero, o sobre la integridad psicofísica o la salud del asegurado. De otro lado, puede ser individual o grupal. El seguro grupal de personas cubre a un grupo determinado y/o su familia o a las personas a su cargo (Art. 115).

Las disposiciones se aplican al caso de muerte, sobrevivencia, rentas u otros vinculados con la vida humana, en cuanto sean compatibles con su naturaleza. En los seguros de personas el asegurador, aun después de pagada la indemnización, no puede subrogarse en los derechos que en su caso correspondan al asegurado contra un tercero como consecuencia del siniestro, con excepción de los gastos efectuados por asistencia médica (Art. 116).

\section{Seguro de salud}

Son seguros de salud en los que el asegurador se obliga, dentro de los límites establecidos en el contrato, a reparar las consecuencias económicas producidas por la enfermedad del asegurado. La prestación del asegurador se puede ejercer mediante reembolso de los gastos derivados de la asistencia médica, una indemnización a suma alzada en caso de invalidez temporal o permanente $\mathrm{u}$ otras contingencias acordadas en la póliza, pero también podrá garantizar al asegurado los servicios de asistencia médica, debiendo poner a disposición dichos servicios y asumir directamente su costo (Artículo 117).

Las enfermedades preexistentes están cubiertas dentro del sistema de seguros y de EPS, como mínimo, hasta los límites del contrato original o anterior. Se entiende por preexistencia, cualquier condición de alteración del estado de salud diagnosticada por un médico, conocida por el titular o dependiente y no resuelta en el momento previo a la presentación de la declaración jurada de salud (Art. 118).

El asegurador está prohibido de exigir exámenes genéticos previos a la celebración de contratos de seguro y no puede condicionar la acep- 
tación, vigencia o renovación de coberturas de seguro a su realización (Art. 119).

\section{Seguro de vida}

\section{a. Definición}

En este seguro el asegurador se obliga, mediante el cobro de la prima y dentro de los límites establecidos en el contrato, a pagar al beneficiario un capital, una renta u otras prestaciones convenidas, en el caso de muerte o supervivencia del asegurado. Puede pactarse sobre la vida propia o la de un tercero, así como sobre una o varias personas (Art. 120).

\section{b. Consentimiento en casos de seguros para tercero}

Si el contratante y el asegurado son personas distintas, se requiere el consentimiento escrito de éste último. Si es menor de edad, es necesaria, además, la autorización también escrita de sus representantes legales. El asegurado puede revocar su consentimiento por escrito en cualquier momento. El asegurador, desde la recepción de dicho documento, cesa en la cobertura del riesgo y el contratante del seguro tiene derecho a la devolución de la prima pagada, salvo la parte correspondiente al periodo de tiempo en que el contrato tuvo vigencia. No se podrá contratar seguros de vida para menores de dieciséis años de edad o personas declaradas judicialmente incapaces. Se exceptúan de esta prohibición, los contratos de seguros en los que la cobertura de muerte resulte inferior o igual a la prima satisfecha por la póliza o al valor de rescate (Artículo 121).

\section{c. Incontestabilidad o indisputabilidad}

Si transcurren dos años desde la celebración del contrato, el asegurador no puede invocar la reticencia o falsa declaración, excepto cuando es dolosa (Art. 122).

\section{d. Declaración inexacta de la edad}

La declaración inexacta de la edad del asegurado acarrea la nulidad del contrato, si su verdadera edad, en el momento de entrada en vigencia del contrato, excede los límites establecidos en la póliza para asumir el riesgo, caso en que se procederá a la devolución de la prima pagada. Sin embargo, si la prima pagada es inferior a la que correspondería, la 
prestación del asegurador se reducirá proporcionalmente. Si, por el contrario, la prima pagada es superior, el asegurador está obligado a restituir el exceso de la prima percibida, sin intereses (Art. 123).

\section{e. Agravación del riesgo}

El seguro de vida no podrá ser modificado o dejado sin efecto, ni la prima incrementada, como consecuencia del cambio de actividad del asegurado que éste no conociera al momento de la celebración del contrato (Art. 124).

\section{f. Suicidio y muerte del tercero por el contratante y/o beneficiario}

El suicidio de la persona cuya vida se asegura, libera al asegurador, salvo que el contrato haya estado en vigencia ininterrumpidamente por dos años. En el seguro sobre la vida de un tercero, está excluida de cobertura la muerte dolosamente provocada por un acto del contratante $\mathrm{y} / \mathrm{o}$ beneficiario (Art. 125).

\section{g. Resolución y liberación del asegurador}

Si por cualquier causa se resuelve el contrato, el asegurador se libera de pagar el capital o la renta pactados, pero debe restituir el valor del rescate que corresponde según la reserva matemática constituida de acuerdo con sus planes técnicos empleados en la póliza siempre que haya sido pactado en la póliza. Esta disposición no será aplicable en los seguros de vida temporales que solo otorguen una cobertura de riesgo (Art. 126).

\section{h. Derechos del Asegurado}

En el seguro de vida, el asegurado tendrá derecho a lo siguiente:

- Derecho de reducción (seguro saldado).- Una vez transcurrido el plazo previsto en la póliza, que no puede ser superior a dos años desde el inicio de vigencia del contrato, no se aplicará la suspensión de cobertura por falta de pago de la prima, sino que produce la reducción del seguro conforme a la tabla o sistema de determinación de los valores previstos en la póliza. La reducción del seguro se produce también cuando lo solicite el contratante, una vez cumplido el plazo 
señalado. Empero, el contratante tiene derecho a la rehabilitación de la póliza, en cualquier momento, antes de la ocurrencia del siniestro.

- Ejercicio del derecho de préstamo.- El asegurador debe conceder al contratante, préstamos sobre la prestación asegurada, conforme a las condiciones fijadas en la póliza, una vez pagadas las dos primeras anualidades de la prima o la que corresponda al plazo inferior previsto en la póliza, hasta el límite del valor de rescate.

- Derecho de rescate.- El contratante que haya pagado las dos primeras anualidades de la prima o la que corresponda al plazo inferior previsto en la póliza puede ejercitar el derecho de rescate, conforme a las tablas o sistema de determinación de los valores previstos en la póliza.

No son obligatorios los derechos de reducción, préstamo y rescate de la suma asegurada en los seguros en forma de renta y en los seguros temporales para el caso de muerte. (Art. 126)

\section{i. Seguro de vida en beneficio de un tercero}

Se puede pactar que el capital o renta a pagarse en caso de muerte, se abone a un tercero sobreviviente, determinado o determinable al momento del evento (Art. 127).

\section{j. Proporción entre beneficiarios}

Si se designaron varios beneficiarios, sin indicación de porcentajes o importes, se entiende que el beneficio es por partes iguales (Art. 128).

\section{k. Falta de designación de beneficiarios}

Si en el momento del fallecimiento del asegurado no hubiese beneficiario designado o por cualquier causa la designación efectuada se hace ineficaz o queda sin efecto, se entiende que comprende a los herederos legales (Art. 129).

\section{Forma de la designación}

La designación de beneficiario debe constar por escrito en la póliza. Es válida aunque se notifique al asegurador después del evento previsto. Si hay cambio de beneficiario será válido siempre que conste en la póliza o que conste en un documento legalizado por notario público (Art. 130). 


\section{m. Liquidación patrimonial}

La existencia de herederos del asegurado y la declaración de insolvencia no afectan el contrato de seguro ni a la designación de beneficiario (Art. 131).

\section{Seguro de accidentes personales}

\section{a. Definición}

Por el seguro la compañía se obliga, dentro de los límites establecidos en el contrato, a indemnizar, mediante el pago de una suma determinada, los daños producidos por una lesión corporal que deriva de causa violenta, súbita, externa y ajena a la intencionalidad del asegurado, que produzca invalidez, temporal o permanente, o muerte. En los casos en que la póliza de seguro contemple una cobertura por invalidez comprenderá la que, derivada de un accidente acaecido durante la vigencia del contrato, se manifieste dentro de los dos años siguientes, siendo válidas las cláusulas que amplíen este plazo. En el seguro de accidentes personales son aplicables los artículos 128 al 131, referentes al seguro de vida (Art. 132).

\section{b. Pago inmediato}

Una vez que el asegurador se pronunció favorablemente frente al siniestro, caso de incapacidad temporal, el asegurado tiene derecho al pago inmediato de los beneficios (Art. 133).

\section{c. Dolo del asegurado o del beneficiario}

Está excluido de cobertura el accidente provocado dolosamente por el contratante, asegurado o el beneficiario (Art. 134).

\section{Seguro de grupo}

En caso de contratación de seguro grupal, en interés exclusivo de los integrantes del grupo, éstos o sus beneficiarios tienen un derecho propio contra el asegurador desde que ocurre el evento previsto (Art. 135).

El contrato fijará las condiciones de incorporación al grupo asegurado. El asegurador está obligado a entregar a cada asegurado un certificado que acredite su incorporación al grupo (Art. 136). 
No son oponibles al asegurado los contenidos contractuales que no le hayan sido informados en el certificado mencionado en el artículo anterior, cuyo contenido mínimo se sujeta a las disposiciones de la SBS (Art. 137).

\section{BIBLIOGRAFÍA}

Clarke, Malcolm. Policies and Perceptions of Insurance. Clarendon Press. Oxford, 1997.

Curso de seguros.- Chartered Insurance Institute.- Elementos de Seguros.- EditorialMapfre.- Madrid, 1973.

Donati, Antígono. Los seguros privados. Librería Bosch. Barcelona, 1960.

Efrén Ossa, G. J.- Teoría General del Seguro.- Editorial Temis.- Bogotá, 1984.

Gonzales Barrón, Gunther H. El contrato de seguro en el Perú. Jurista editores. Lima, 2002.

Mehr, Robert I. Life Insurance. Business Publications, Inc.- Dallas, Texas, 1977.

Morandi, Juan Carlos Félix. Estudios de Derecho de Seguros. Ediciones Pannedille, Buenos Aires, 1971.

Osorio Ruiz, Zaida. Contrato de seguro. San Marcos. Lima, 1999.

Richter Valdivia, Pedro y Castillo Freyre, Mario. El contrato de seguro. Palestra. Lima 2006.

Stiglitz, Rubén S.- Teoría y Práctica del Derecho Seguros.- La Ley.- Buenos Aires, 2004.

Villa Zapata, Walter. Comentarios a la legislación de seguros. San Marcos. Lima, 1999.

César Vivante. El contrato de seguro. Ediar. Buenos Aires, 1952. 